\title{
PREDICTION OF TWO-PHASE PRESSURE DROP USING ARTIFICIAL NEURAL NETWORK
}

\author{
M.A. El-Kadi ${ }^{1}$, M.A. Husien ${ }^{1}$, S.M. El-Behery ${ }^{1}$ and H. Farouk ${ }^{2}$ \\ ${ }^{1}$ Mechanical Power Engineering Dept., Faculty of Engineering, Menoufia University, \\ Shebin Elkom, Egypt. \\ ${ }^{2}$ MAGAPETCO - Magawish Petroleum Co., Cairo, Egypt
}

\begin{abstract}
:
In the present paper an Artificial Neural Network (ANN) model is proposed to predict the two-phase pressure drop in oil and gas field. In this model, the effect of number of hidden layers and number of neurons in each layer is selected to generate independent results. In addition, the selected database contains 7581 data sets selected from four different sources from which 1165 data sets are collected from the flowing wells of Magapetco at East Esh Mallaha Marine (EEMM) field. The comparison between ANN predictions and other popular models reveals that the ANN model can predict the pressure drop with fair accuracy. Furthermore, the proposed model is used to predict the pressure distribution along the wall of flowing wells as well as the bottom hole flowing pressure and good accuracy was obtained.
\end{abstract}

Keywords:- Neural network, pressure drop, two-phase, oil and gas.

\section{NTRODUCTION}

The (ANN) was used since 1990s to do the same function of empirical and mechanistic correlations for predicting the flowing well bottom hole pressure with some known well parameters. In 1995 Ternyik et al. [1] explored application of a new ANN model to predict the bottom hole flowing pressure. They used the back propagation network and trained it with Mukharjee and Brill [2] experimental data. In 2002 another study done by Shippen and Scott [3], they developed a three layer back propagation ANN to predict the two-phase holdup in a horizontal flow. They used 627 holdup measurements for network training. Osman [4] proposed a three layer BP network predict the liquid holdup and flow regime in horizontal multiphase flow using 199 experimental data sets.

Osman et al. [5] introduced another network to predict the flowing bottom-hole pressure in vertical multi-phase flow. They compared their network with the conventional empirical and mechanistic models showed that the ANN was the best. Ozbayoglu and Ozbayoglu [6] presented different types of ANN to predict the frictional pressure loss and the flow regime of horizontal multi-phase flow. Mohammadpoor et al. [7] conducted a new ANN to predict the bottom-hole flowing pressure in vertical multiphase oil well in Iranian oil fields. He tested different layers neurons of ANN and various training functions and used the best of them which had the minimum error.

Ashena et al. [8] trained ANN with varying the number of neurons to predict the pressure drop in annular multi-phase flow based on Iranian oil field data sets. Adebayo et al. [9] performed a comparison between different training functions, where, the "trainlm" function was selected as the best function. They used a total of 795 data sets from well test data to predict the bottom-hole pressure in vertical wells. Li et al. [10] trained different neural network models corresponding to different flow regimes utilizing a new model for bottom hole flowing pressure prediction. Ebrahimi and Khamehchi [11] proposed an ANN to compute the pressure drop in multiphase vertical oil well. A total number of 1740 data collected from the Middle East region wells were used to train and test the ANN.

All the previous ANN models achieved higher accuracy when compared with conventional pressure drop estimation correlations.

Noted that most of the previously mentioned ANN models used the total pressure drop in the used pipe or well bore as one segment which may reduce the accuracy of the obtained results for deviated wells. For this reason the pipeline or well bore used in this study divided into segments by the rule of traverse method as will be explained later.

\section{MATHEMATICAL MODEL}

In the human brain, a typical neuron collects signals from others through a host of fine structures called dendrites. The neuron sends out spikes of electrical activity through a long, thin stand known as an axon, which splits into thousands of branches. At the end of each branch, a structure called a synapse converts the activity from the axon into electrical effects that inhibit or excite activity in the connected neurons. Neural Network is an information processing model that is inspired by the biological nervous systems, such as the human brain's information processing mechanism. 
An ANN is configured for a specific application, such as pattern recognition or data classification, through a learning process. The key element of this model is the novel structure of the information processing system. It is composed of a large number of highly interconnected processing elements (neurons) working in unison to solve specific problems. ANNs, like people, learn by example. A neuron performs two simple tasks which are weighted summation of its input array and the application of a sigmoid function (Sshaped) to this summation to give an output which can serve as input to other neurons.

An ANN consists of an input layer, an output layer, and one or more hidden layers. The input layer contains an array of variables into which the input data of the system is read from an external source. Similarly, the predicted data or results, which can be multiple vectors, are written in the output layer. Initially, the input layer receives the input and passes it to the first hidden layer for processing. The processed information from the first hidden layer is then passed to the other hidden layers for processing, as shown in Fig. 1. Finally,

During the training process, the weights are adjusted in order to make the actual outputs (predicated) close to the target (measured) outputs the output layer receives information from the last hidden layer and sends the results to an external source. All the hidden layers have no direct connections to the outside world and the entire processing step is hidden from us Fig. 2

The sequence of the ANN modeling is passing through five steps which are data collection, data preparation, building network, training network, and testing network. Collecting and preparing sample data is the first step in designing ANN models. After data collection, data preprocessing procedures are conducted to train the ANNs more efficiently [12].

Data Normalization procedure before presenting the input data to the network is generally a good practice, since mixing variables with large magnitudes and small magnitudes will confuse the learning algorithm on the importance of each variable and may force it to the designer specifies the number of hidden layers, neurons in each layer, transfer function in each layer, training function, weight/bias learning function, and performance function

of the network. The next step is to test the performance of the developed model. At this stage unseen data are exposed to the model.

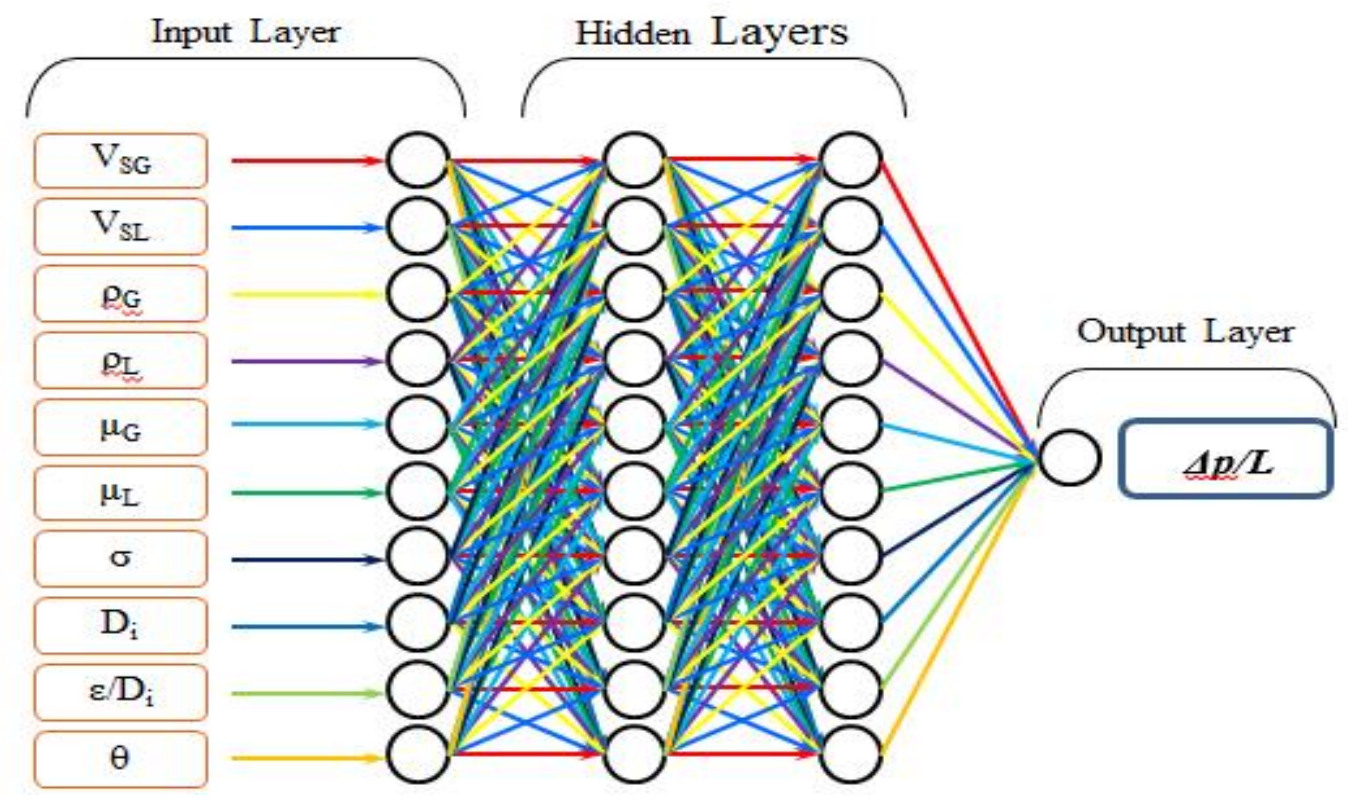

Fig. 1 ANN inputs, outputs, and hidden layers.

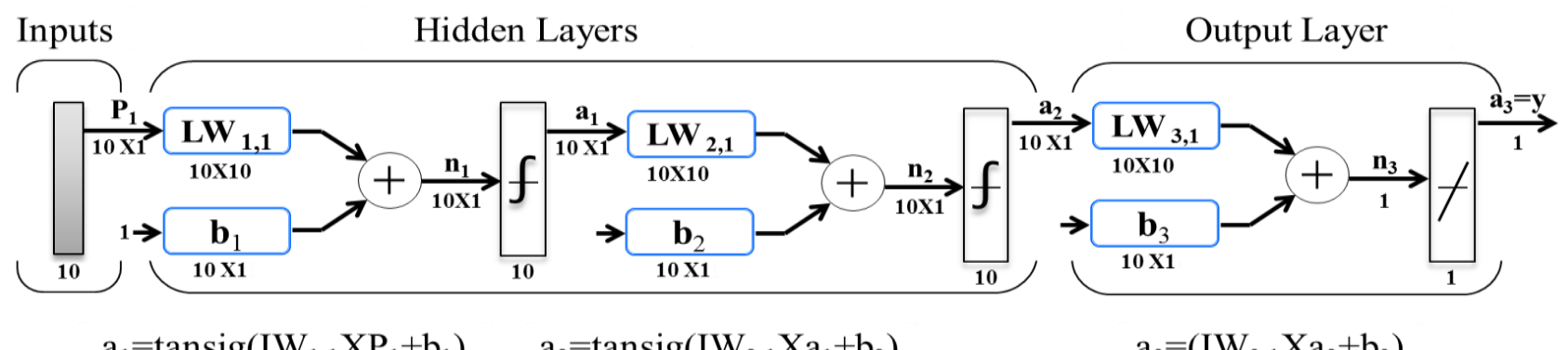

$$
\mathrm{a}_{1}=\operatorname{tansig}\left(\mathrm{IW}_{1,1} \mathrm{XP}_{1}+\mathrm{b}_{1}\right) \quad \mathrm{a}_{2}=\operatorname{tansig}\left(\mathrm{IW}_{2,1} \mathrm{Xa}_{1}+\mathrm{b}_{2}\right) \quad \mathrm{a}_{3}=\left(\mathrm{IW}_{3,1} \mathrm{Xa}_{2}+\mathrm{b}_{3}\right)
$$

Fig. 2 ANN inputs, outputs, hidden layers, and functions. 


\subsection{Data Collection}

A Total 7581 data sets are collected from four different independent sources. The distribution of these data is given in table 1.

Table 1. The detailes of collected data distribution.

\begin{tabular}{|l|l|l|l|l|l|}
\hline Data Source & $\begin{array}{l}\text { Stanford University } \\
\text { Data Bank [19] }\end{array}$ & $\begin{array}{l}\text { Weihong } \\
\text { Meng [20] }\end{array}$ & $\begin{array}{l}\text { Beggs and } \\
\text { Brill [21] }\end{array}$ & EEMM & Total \\
\hline Number of Data sets & $\mathbf{5 6 5 8}$ & $\mathbf{1 7 6}$ & $\mathbf{5 8 2}$ & $\mathbf{1 1 6 5}$ & $\mathbf{7 5 8 1}$ \\
\hline
\end{tabular}

Field data were collected from Magapetco EEMM field flowing wells. The memory gauge inserted inside well bore by means of wire line to read and record the pressure and temperature along the well bore depth. At that job there are many stops at predefined depth to record the average pressure and temperature at this location with time.

The pressure and temperature records then referenced to its depth along the wellbore. The pressure and temperature with properties of oil, gas and water flowing inside the well are used to calculate the rest of data required to be the same form as other data banks. The data were used to be the input of artificial neural network

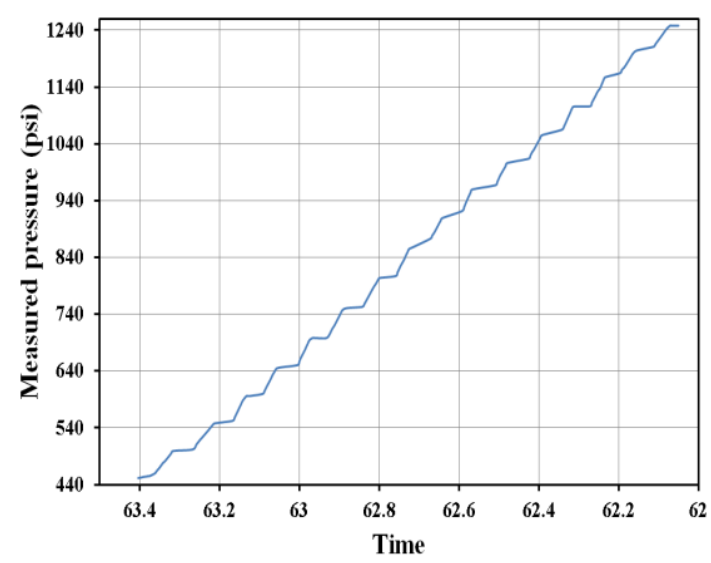

a) EEMM-1A flowing Pressure distribution with time. training. Then that data were used for comparison with other two phase pressure drop models, Fig. 3.

2.2. Data pre-Processing and post-Processing Network-input processing functions transform inputs into a better form for the network use. Processing functions associated with a network output transform targets into a better form for network training, and reverse transformed outputs back to the characteristics of the original target data. The most common preprocessing data functions are minimummaximum and mean and standard deviation functions. The chosen transfer function is minimum and maximum function.

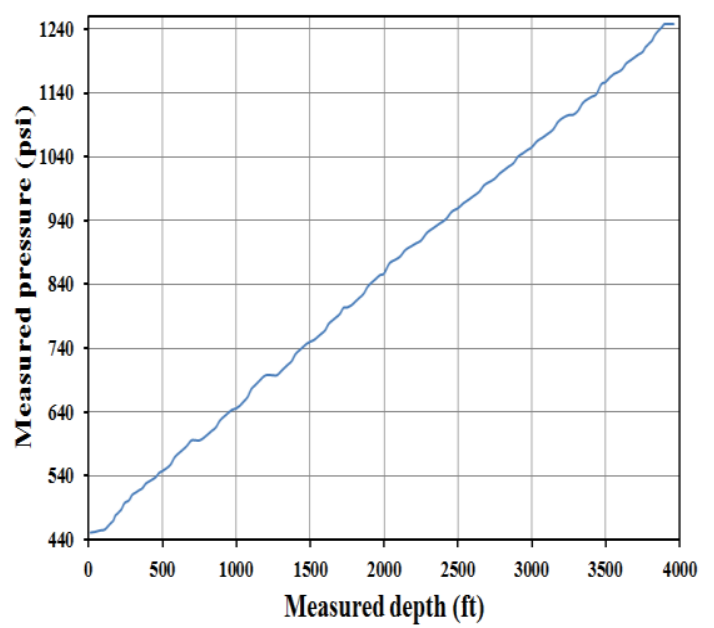

b)EEMM-1A flowing Pressure distribution with depth.

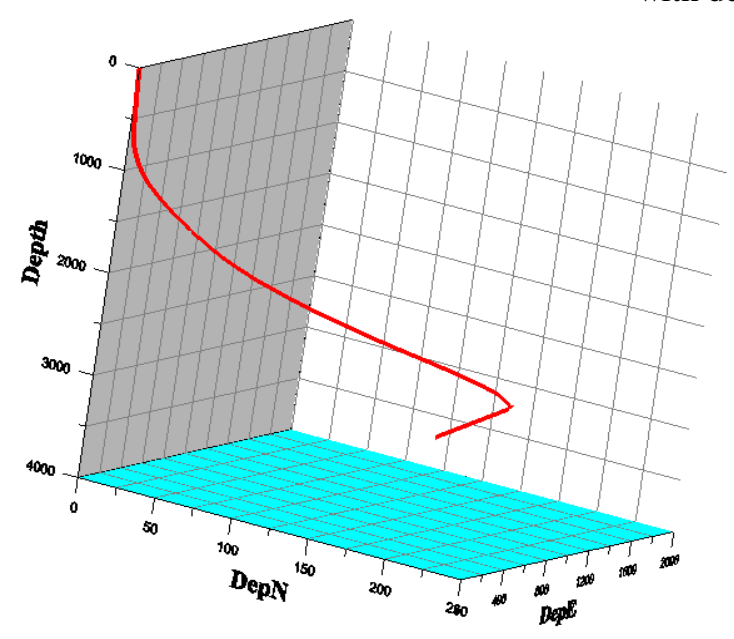

c) EEMM-1A 3D graph.

Fig. 3. Field data collection and well 3d graph for Magapetco well EEMM-1A. 


\subsection{Building Network}

In the current study, back propagation feed forward network is used. The number of hidden layers and the number of neurons in each layer are very important parameters when building the network. In the current study, comparisons are carried out between the model accuracy using one, two, and three hidden layers and number of neurons in each layer from 10 to 70 neurons, as shown in Fig. 4. From this figure it can be seen that the model accuracy don't changed greatly when the neurons in increased from 60 to 70 neurons. Therefore, 70 neurons can be used for the network with fair accuracy. The figure shows also that the accuracy of two hidden layers is higher than that of three hidden layers. Therefore, a two hidden layers network is chosen in the current study.

For the training functions the default function (trainlm) is used. trainlm is a network training function that updates weight and bias values according to Levenberg-Marquardt optimization. trainlm is often the fastest backpropagation algorithm in Matlap program toolbox, and is highly recommended as a first-choice supervised algorithm, although it does require more memory than other algorithms.

As the percentage of dividing the inputs to training, validating, and testing tested for the available divisions, the best was 70, 15, and 15 for training, validating, and testing respectively. The selected network is shown in Fig. 5.

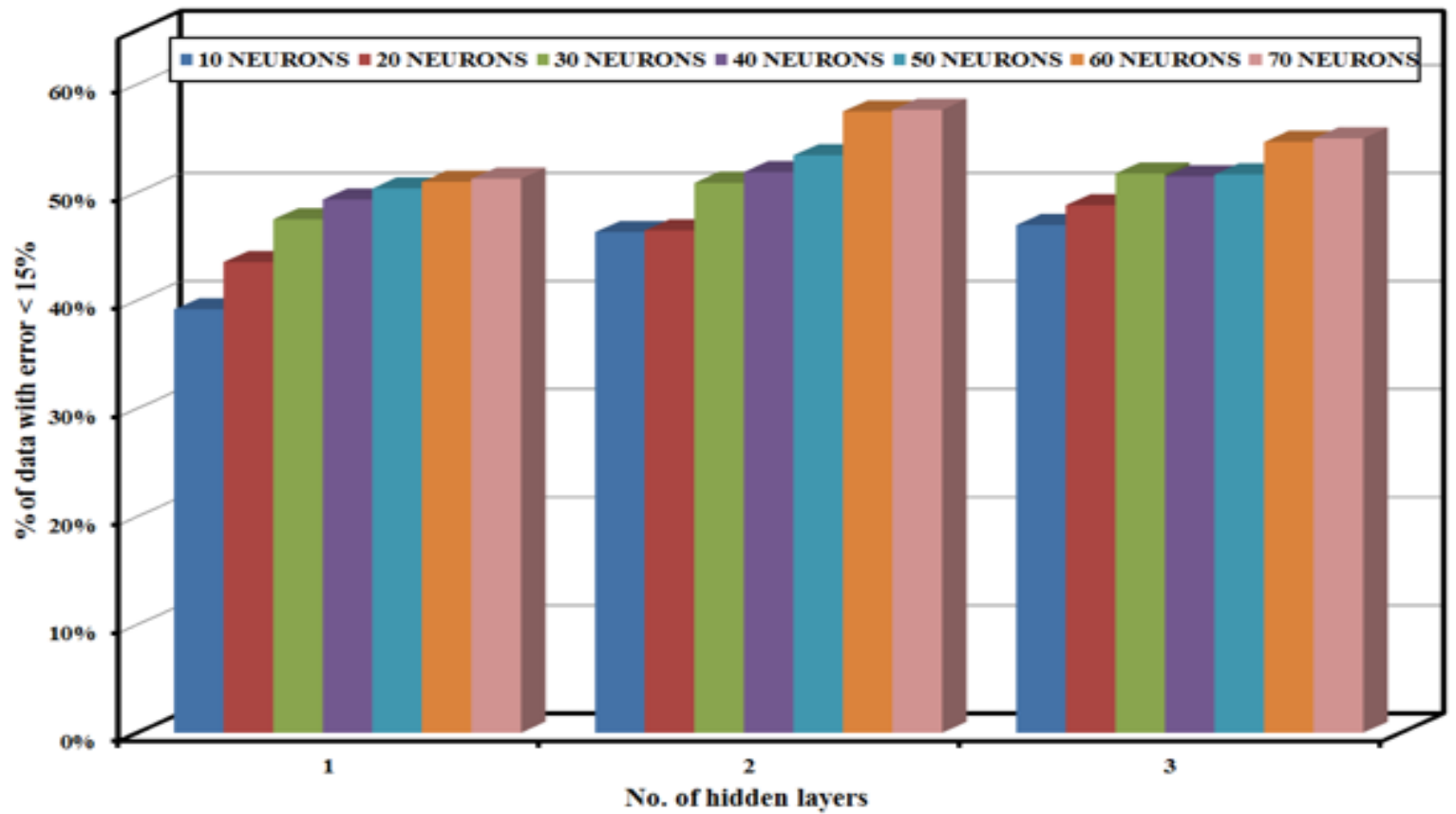

Fig. 4 Effect of number of hidden layers and number of neurons on ANN accuracy.

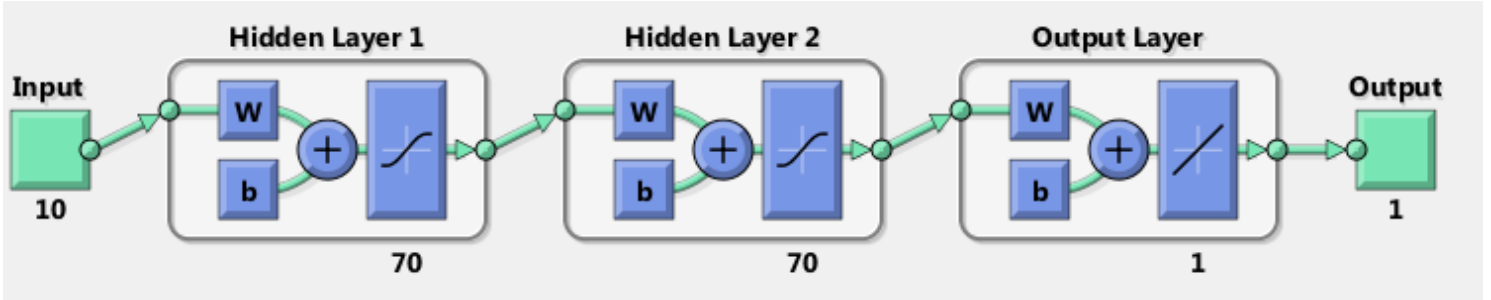

Fig. 5. Final selected ANN.

\subsection{Training Network}

There are two network training types namely supervised and unsupervised training. In the supervised training, the network feed by inputs and corresponding targets to predict the outputs of these inputs. Then, the target compared with the output leading to modifying the weights for each layer to reduce the error between output and target. While in the unsupervised training, the weights and biases are modified in response to network inputs only. There are no target outputs available. Most of these algorithms perform clustering operations. In the current study the appropriate type of training is the supervised training type to predict the pressure drop from the two-phase flow properties inputs.

This network uses the following procedure to achieve target. First step is to enter the input data, and calculate its corresponding output; this step is named feed forward process. The next step is to calculate the error between the targets and outputs. If the sum-squared-error between outputs and corresponding targets isn't in the required 
range, then the error must be minimized by readjusting the weights beginning with the last layer. The same process of calculating error is repeated back-propagated for the previous layers till reaching the input layer. This process named backpropagation. For more details in back-propagation process, after calculating the outputs resulted from providing the network with inputs, the error between each output and corresponding target is determined as:

$$
E=\left(T_{i}-Y_{i}\right)
$$

Where: $T_{i}$ is the outputs, $Y_{i}$ is the target

Then, the weights and biases are readjusted from network learning process as follows:

$$
\Delta \mathrm{W}_{\mathrm{i}}=\mathrm{W}_{\mathrm{i}+1}-\mathrm{W}_{\mathrm{i}}
$$

Where: $\mathrm{W}_{\mathrm{i}+1}$ is the new adjusted weight, $\mathrm{W}_{\mathrm{i}}$ is the old (original) weight

$$
\Delta w_{i}=\mathrm{L}_{\mathrm{R}} \mathrm{E} \mathrm{X}
$$

Where: $L_{R}$ is a small constant (Example $0.01)$ named learning rate.

Then, the new weights can be calculated from Eq. (2). Propagate backward to the previous layer by also calculating errors and readjusting its weights. Doing the same for all layers until reaches the first inputs layer by readjusting the weights. Step by step the errors between outputs and targets will be in the desired range. Then that will be the required network.

To avoid over fitting which makes the network is special for a certain data which are inputted in the training data, the validation data rule appeared. As shown in Fig. 6, the mean square error of the training inputs still decreases but the training is stopped affected by the validation mean square error begin to increase and this is the controlling point in the training process to avoid over fitting.

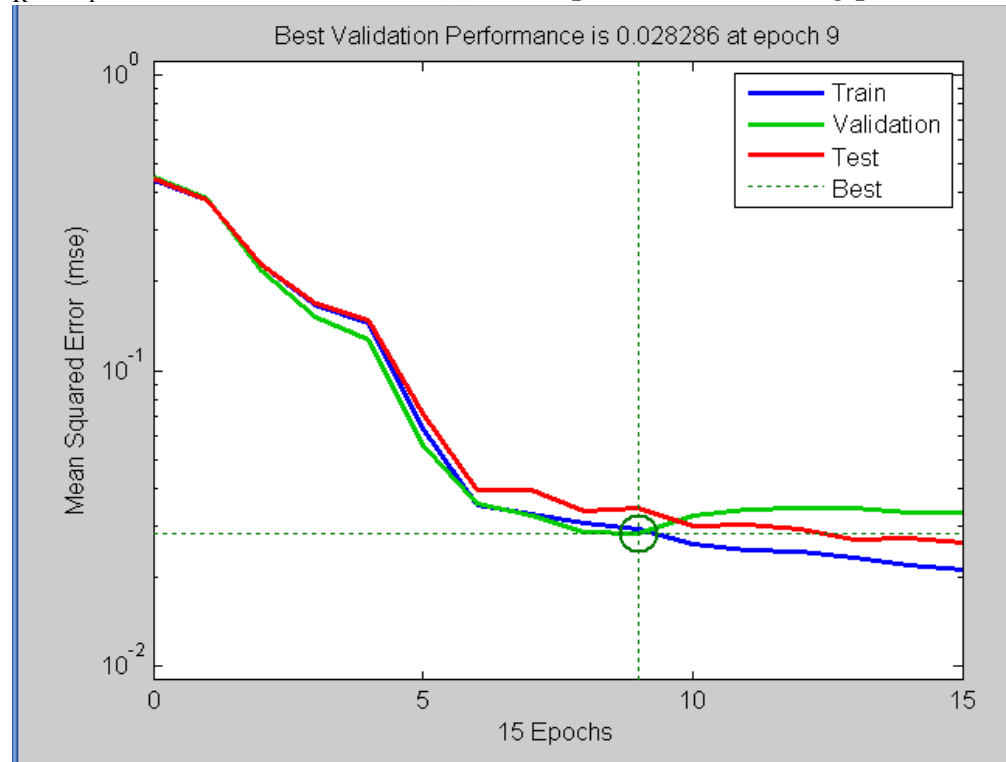

\subsection{Testing network}

Fig. 6. Training stop when validation MSE start to increase.

The network input data divided into three divisions: training, testing, and validation. Usually the three division ratios are $70 \%, 15 \%, 15 \%$ for training, testing, and validation respectively. The testing division data sets ensure the accepted performance of the network through inputting a new data to the network which don't included in the training data sets, as shown in Fig. 7. The effect of training, testing, and validation ratios on the performance of the network is checked and resulted in that no significant effect was found as shown in Fig. 8. Therfore, the default value of divisions which is $70 \%, 15 \%, 15 \%$ for training, testing, and validation respectively, is chosen.

For accurate results the range of application of the ANN model must be within the minimum and maximum values of the training input variables. The minimum and maximum values of input variable are tabulated in table 2 .

Table 2. Minimum and maximum values of network input variable.

\begin{tabular}{|l|l|l|l|l|l|l|l|l|l|l|}
\hline variable & $\mathbf{V}_{\mathbf{S G}}$ & $\mathbf{V}_{\mathbf{S L}}$ & $\mu_{\mathbf{G}}$ & $\mu_{\mathbf{L}}$ & $\rho_{\mathbf{G}}$ & $\rho_{\mathbf{L}}$ & $\sigma$ & $\mathbf{D}$ & Angle & $\varepsilon / \mathbf{D}$ \\
\hline Maximum & 228.2081 & 23.7984 & 0.1799 & 95.8900 & 2.1493 & 62.4482 & 72.60 & 5.5197 & $90^{\circ}$ & 0.0017 \\
\hline Minimum & 0.0039 & 0.0010 & 0.0113 & 0.6257 & 0.0708 & 48.0997 & 20.92 & 0.5000 & $-90^{\circ}$ & 0.0000 \\
\hline
\end{tabular}



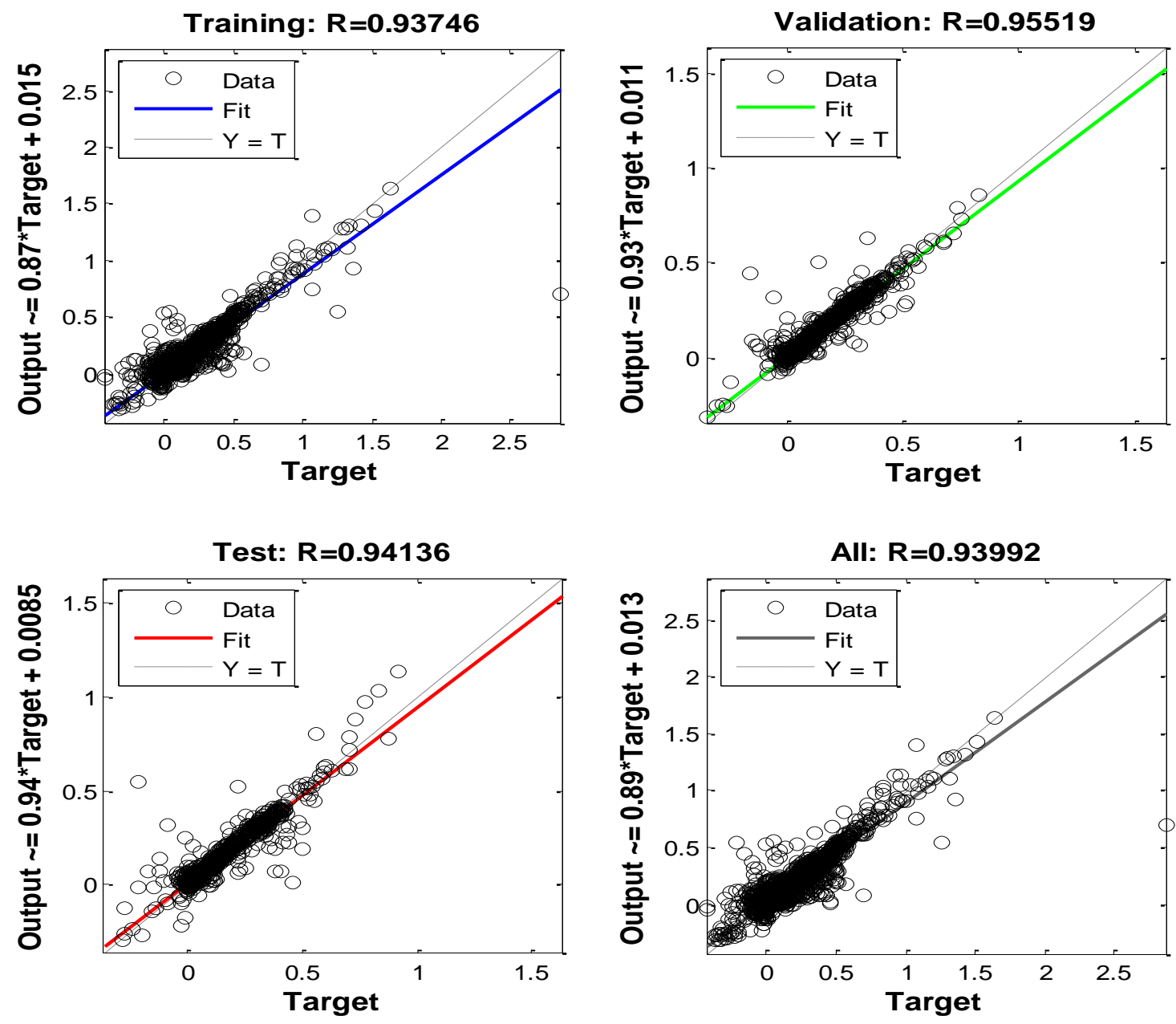

Fig. 7. Training, testing, validation divisions and total outputs accuracy.

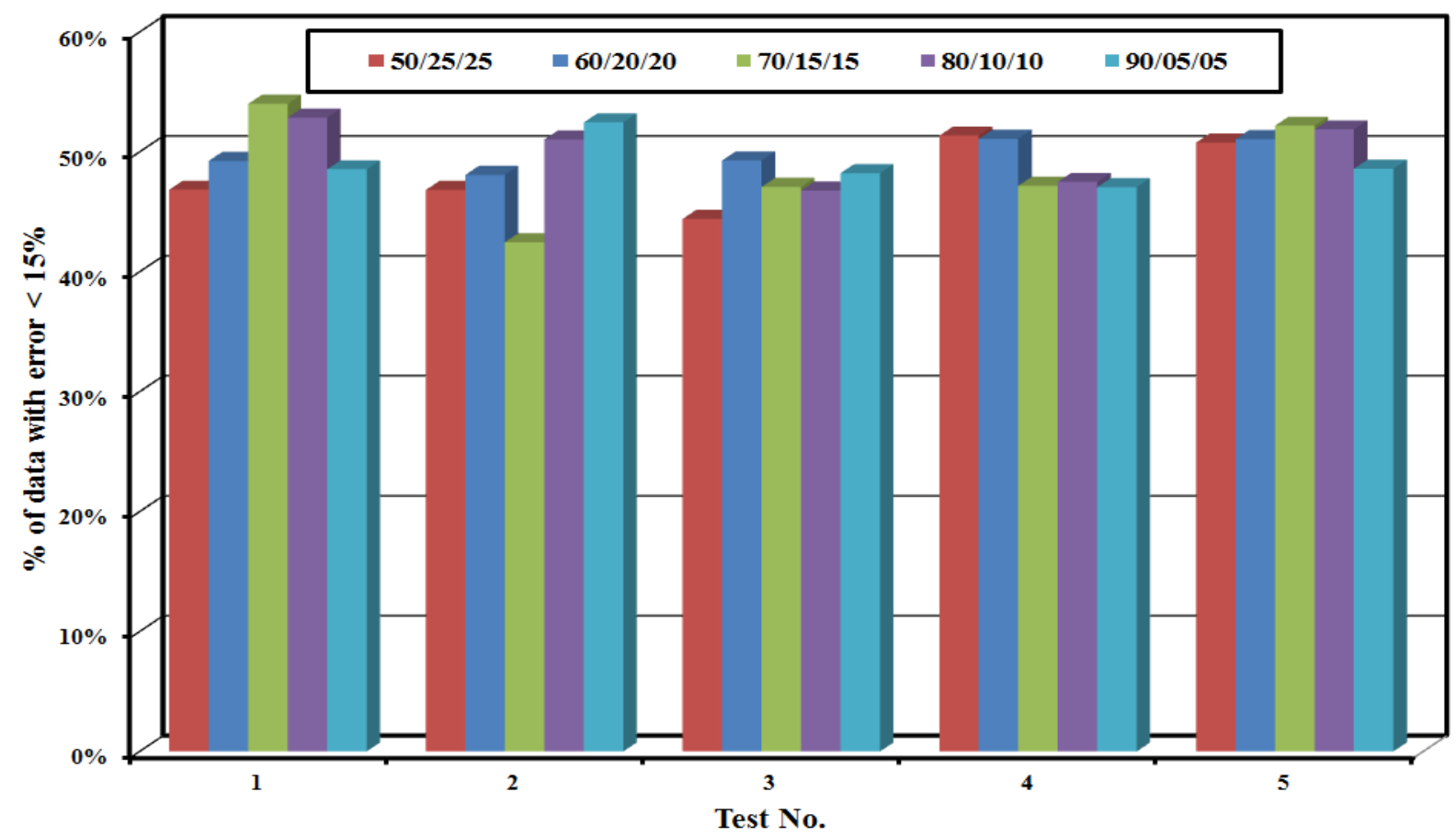

Fig. 8. Effect of training, testing, and validation divisions on ANN accuracy. 


\section{RESULTS AND DISCUSSION}

Six models of two-phase flow pressure drop models were applied on the collected data to select the most accurate model. The six models are: 1. Homogenous model [13] 2. Gray model [14] 3. Beggs and Brill model [15] 4. Duns and Ros model [16] 5. Mukherjee and Brill model [17] 6. Petalas and Aziz model [18]. The collected data was gathered from four different sources. Figure 9 shows the collected data classified based on flow regime and inclination angle. As illustrated in the figure, the data set cover the wide range of flow regimes and inclination angles.
The first data source is the Stanford university multiphase flow data bank [19]. This data bank contains 5658 data sets and used based on permission from prof. Khaled Aziz. The second source is a published paper of Meng [20], and this data set contains 176 data sets. The third data source is from Beggs [21] and contains 582 data sets. The fourth and last source is Magapetco co. field (East Esh Mallaha Marine). The collected data from EEMM is 1165 data sets.

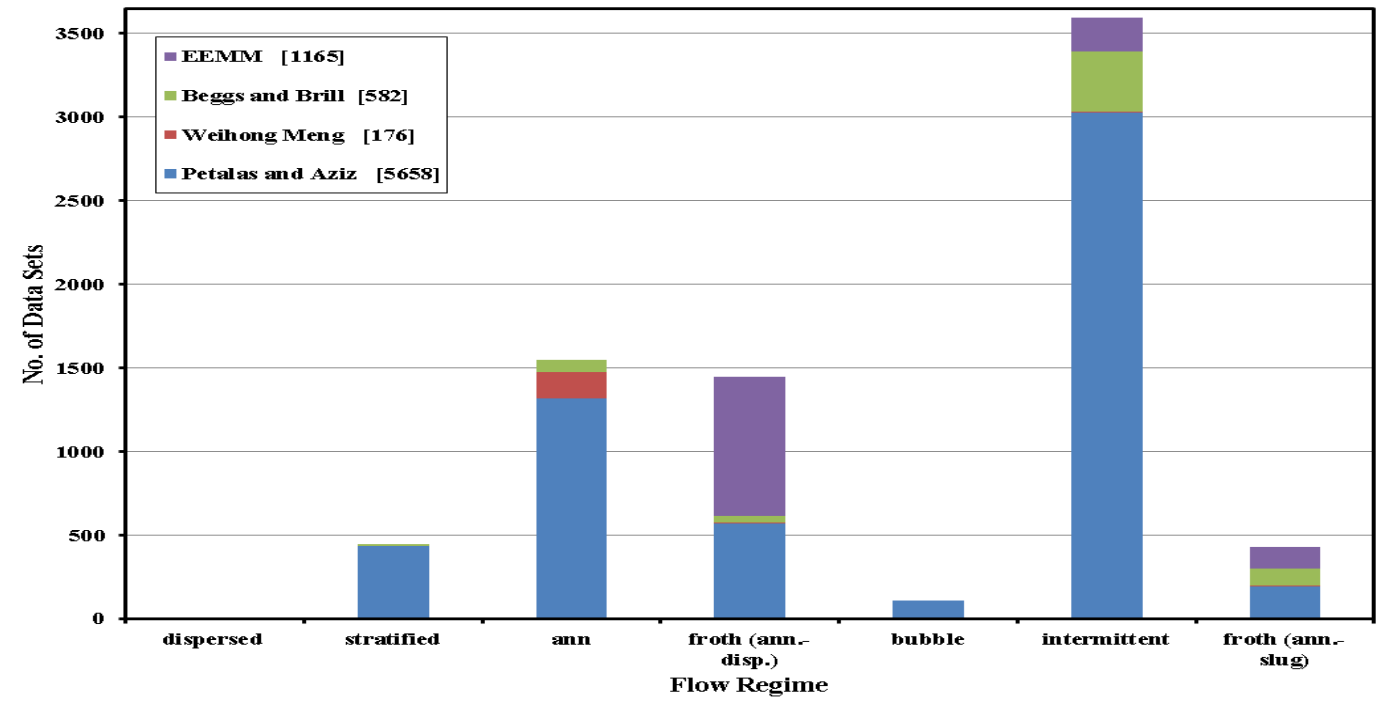

a) Based on flow regime.

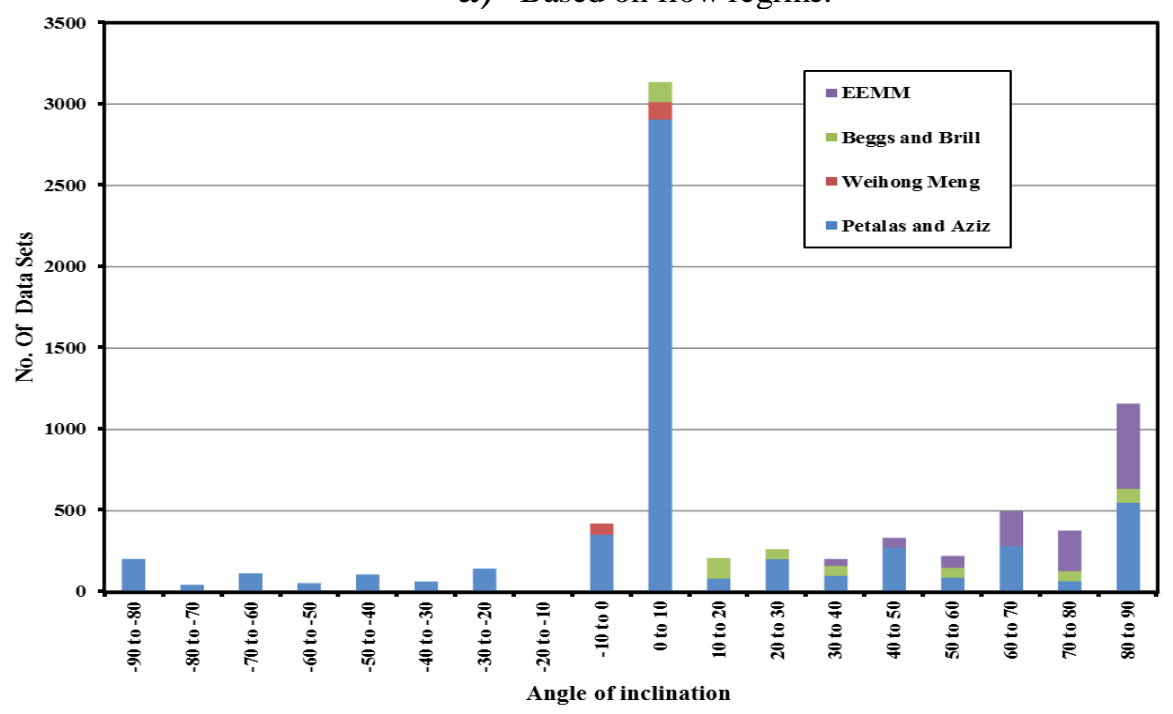

b) Based on inclination angle.

Fig. 9. Collected data distribution as flow regime and inclination angles. 


\subsection{Comparison between Pressure Drop Models}

The accuracy of the tested models is presented in Fig. 10. The figure shows a direct comparison between measured and predicted pressure drop data. It can be seen from this figure that the ANN model gives the most accurate results.

To quantify the accuracy of the tested models, the ability of these models to predict the pressure drop, data with $15 \%$ and $30 \%$ accuracy is presented in Fig. 11 for different flow regimes and in Fig. 12 for different inclination angles.

It can be seen from this figures that the ANN model predicts $48.27 \%$ of the data with an accuracy of $15 \%$ and $63.39 \%$ of the data with an accuracy of $30 \%$ for different flow regimes Fig. 11. Despite this accuracy is low, it is quite acceptable in multiphase where many parameters act. Figure 11 shows also that the highest accuracy is found for dispersed and bubble flow regimes. These results may be attributed to the homogeneity of these regimes. In addition, the accuracy of all models was low in downhill flows (negative inclination angles) Fig. 12. This may be due to that the stratified flow regime is the most dominated in this inclination angles.

\subsubsection{Statistical Analysis}

Statistical analysis was carried out for the results of all two-phase pressure drop models and this analysis is presented in the table 3. The parameters of analysis presented in the next equations.

- $\quad$ Average Relative Percent Error (APE)

$$
A P E=100 \times \frac{1}{N} \sum_{i=1}^{n} E_{i}
$$

Where:

$$
E_{i}=\left[\frac{(\Delta P)_{a c t, i}-(\Delta P)_{e s t, i}}{(\Delta P)_{a c t, i}}\right]
$$

- Absolute Average Relative Percent Error (AAPE)

$$
A P P E=100 \times \frac{1}{N} \sum_{i=1}^{n}\left|E_{i}\right|
$$



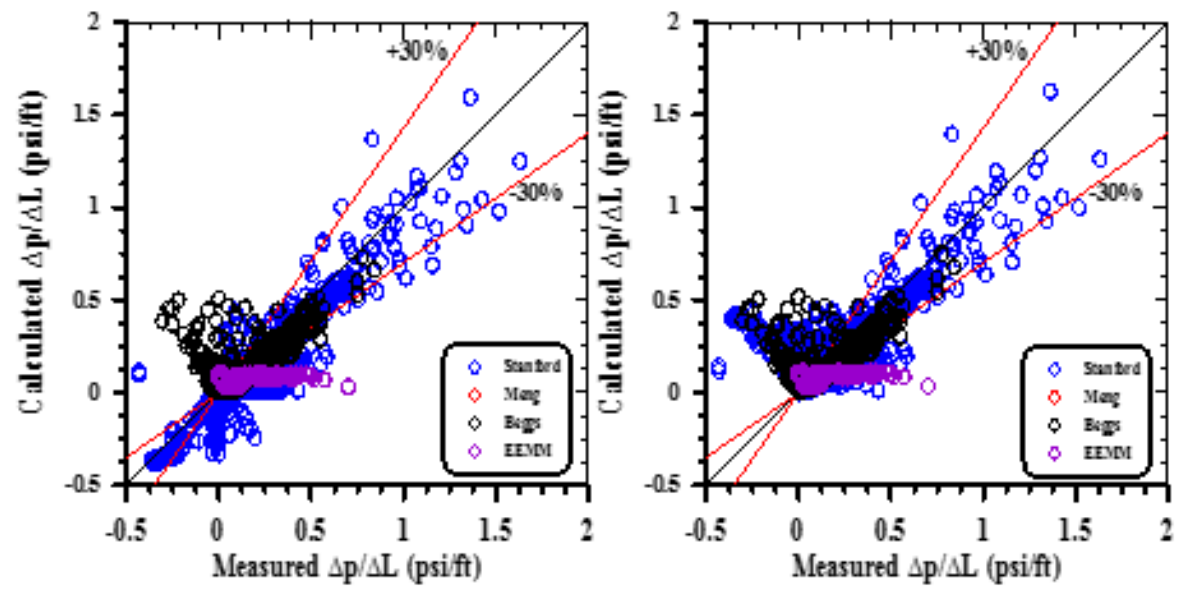

a) Homogeneous model [13].

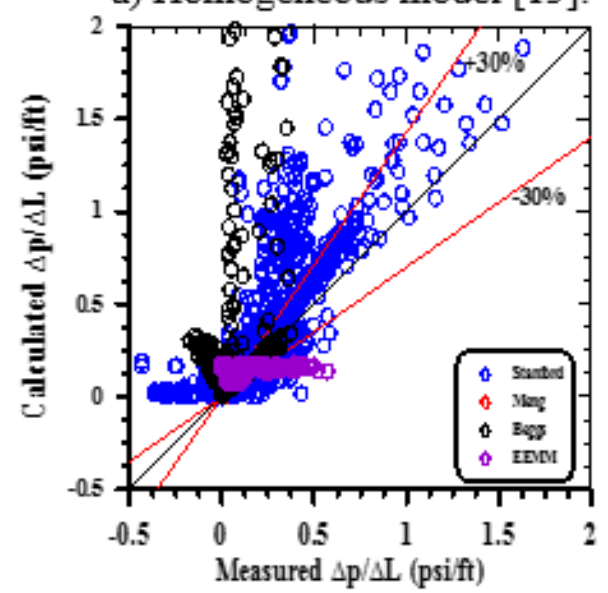

e) Mukherjee and Brill model [17]

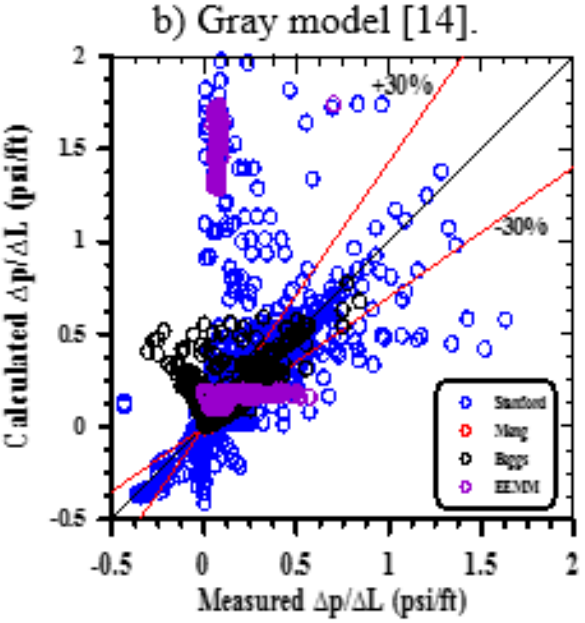

f) Petalas and Aziz model [18].

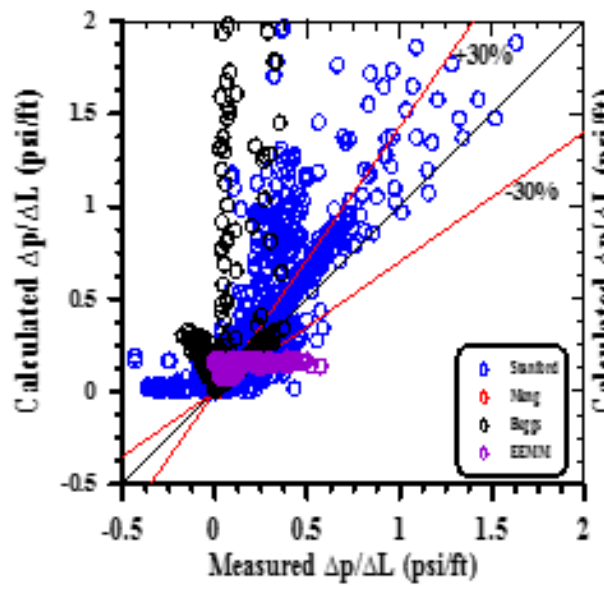

c) Beggs and Brill model [15].

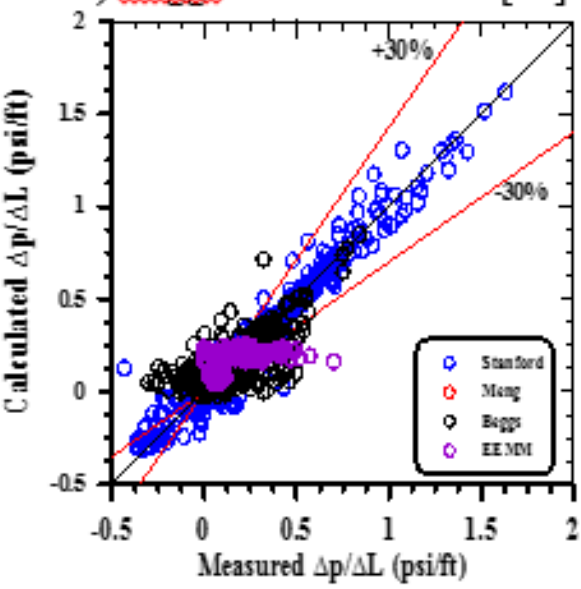

g) ANN model [this work]

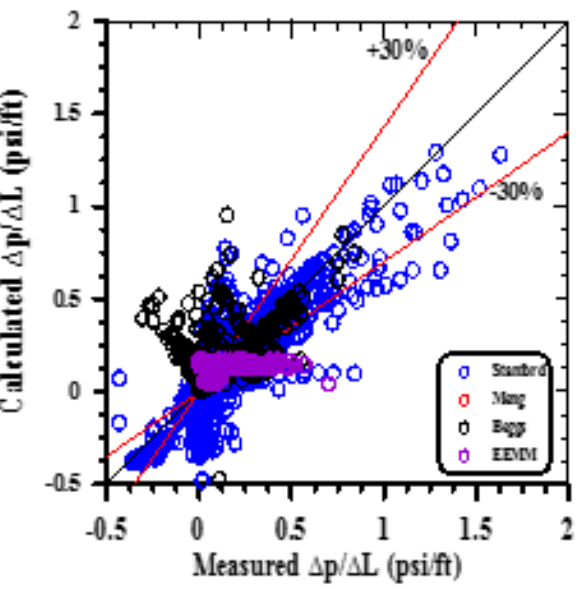

d) Duns and Ros model [16]

Fig. 10. Comparison between two-phase pressure drop models measured and calculated data. 
M.A. El-Kadi, M.A. Husien, S.M. El-Behery, H. Farouk "PREDICTION OF TWO-PHASE PRESSURE ...”

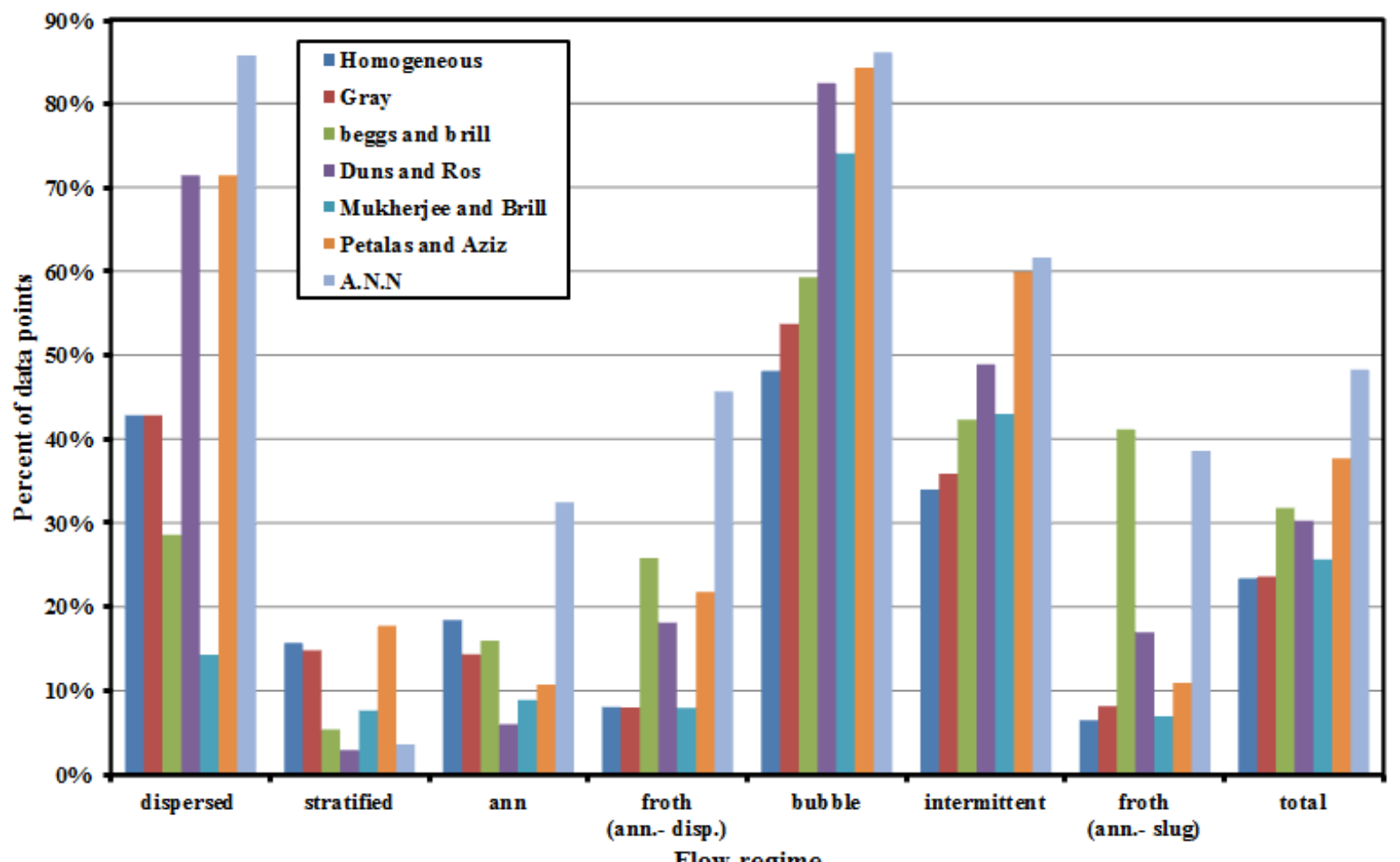

a) $15 \%$ accuracy.

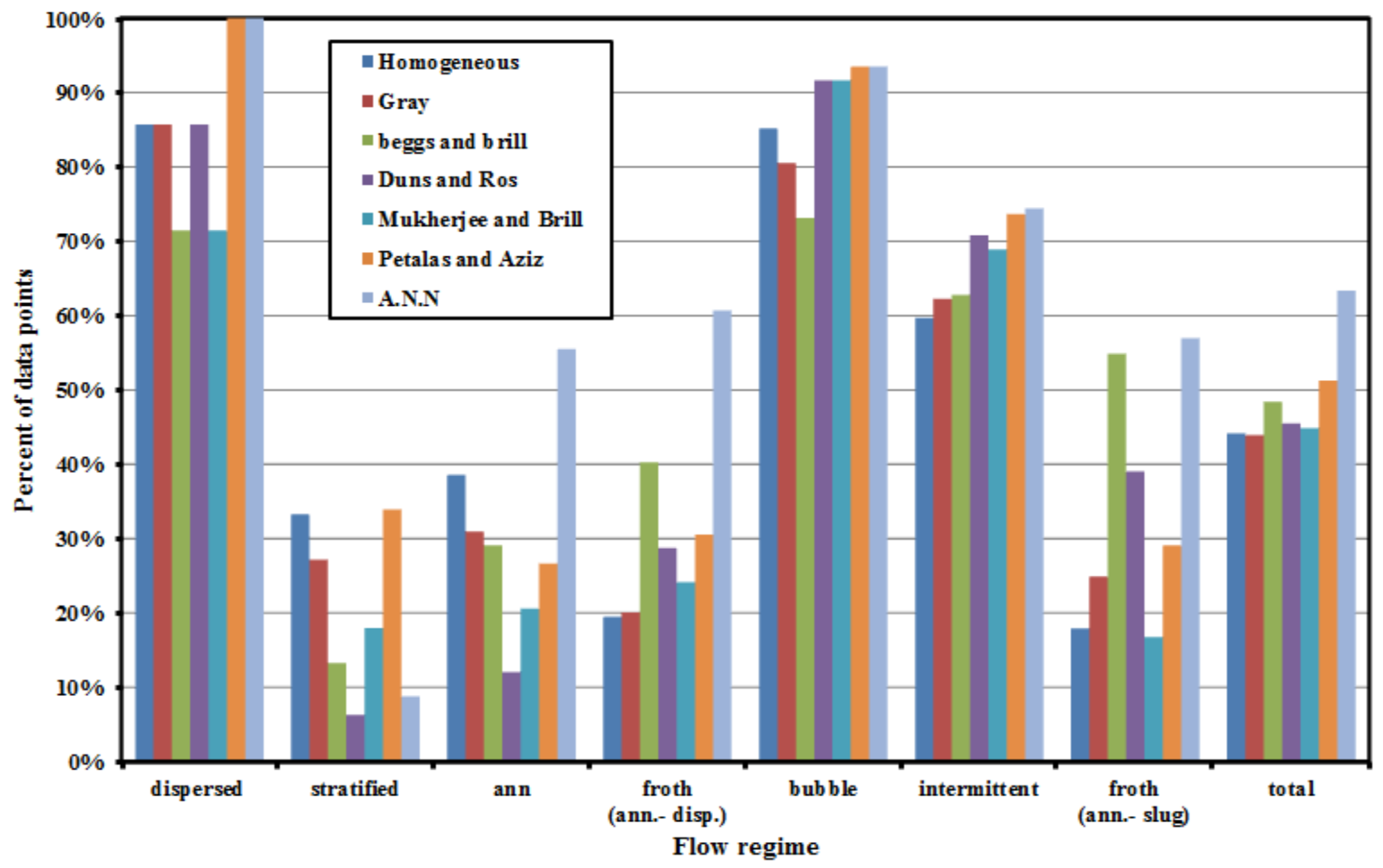

b) $30 \%$ accuracy.

Fig. 11. Comparison of selected methods' ability to predict experimental pressure drop for different flow regimes. 
M.A. El-Kadi, M.A. Husien, S.M. El-Behery, H. Farouk "PREDICTION OF TWO-PHASE PRESSURE ...”

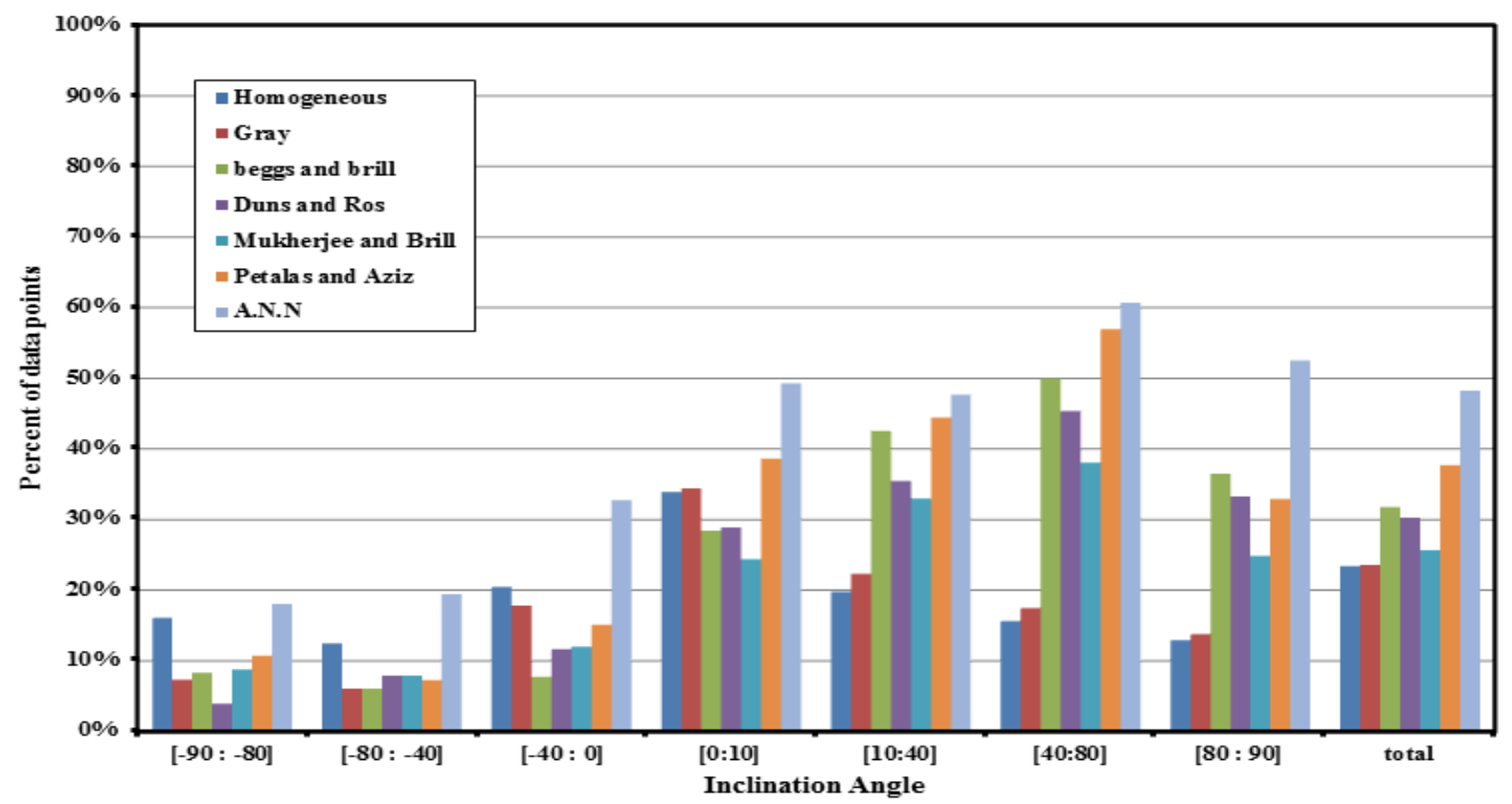

a) $15 \%$ accuracy.

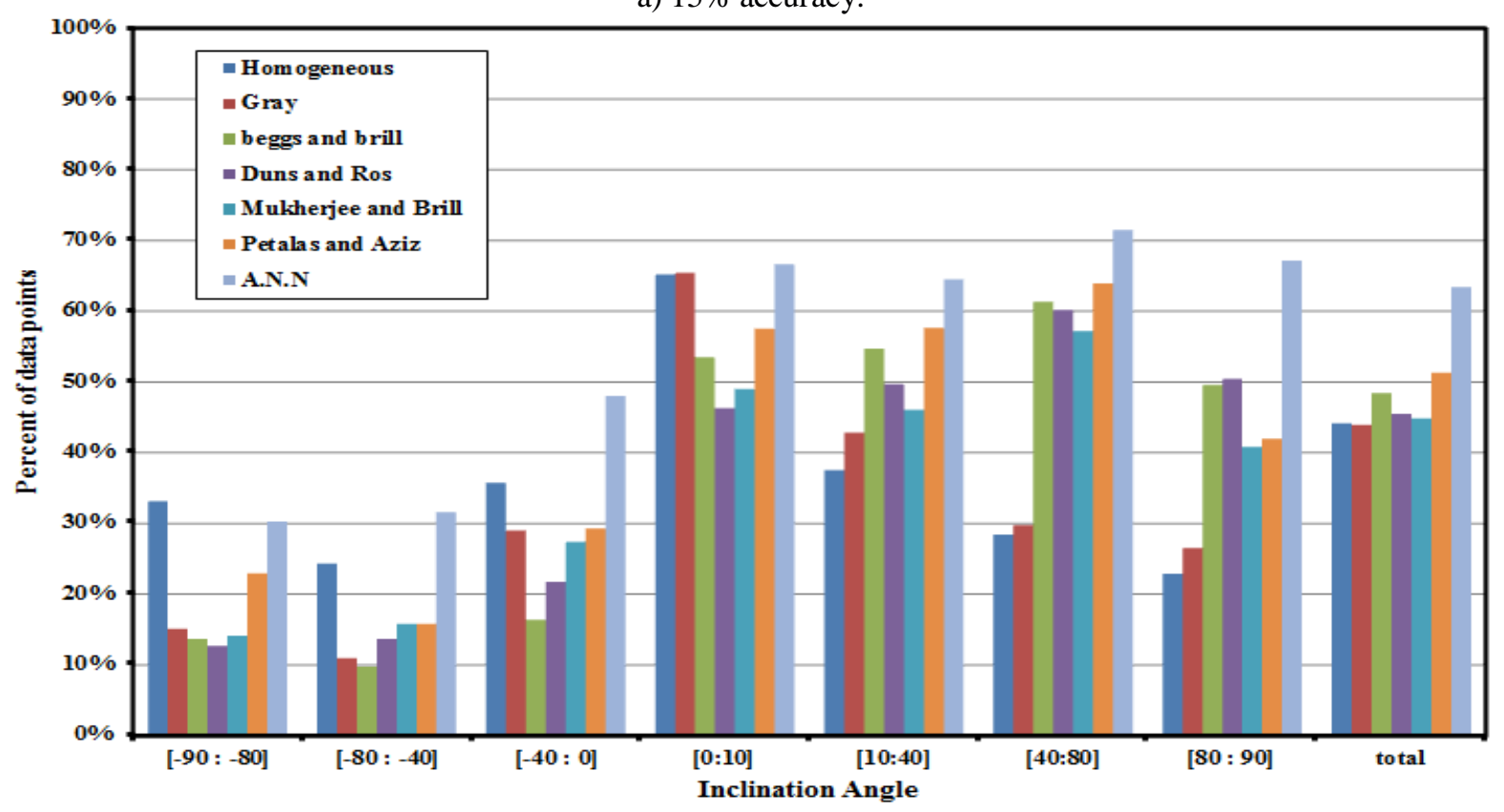

b) $30 \%$ accuracy.

Fig. 12. Comparison of selected methods' ability to predict experimental pressure drop for different inclination angles.

- Root Mean Square Error (RMSE)

$$
R M S E=\sqrt{\frac{1}{N} \sum_{i=1}^{n} e_{i}^{2}}
$$

Where:

Where: $\quad e_{i}=(\Delta P)_{a c t, i}-(\Delta P)_{e s t, i}$

- The Correlation Coefficient (R)

$R$

$=\frac{\sum_{i=1}^{n}\left[(\Delta P)_{a c t, i}-\overline{(\Delta P)}_{a c t}\right]\left[(\Delta P)_{e s t, i}-{\overline{(\Delta P)_{e s t}}}\right]}{\sqrt{\sum_{i=1}^{n}\left[(\Delta P)_{a c t, i}-\overline{(\Delta P)_{a c t}}\right]^{2}} \sqrt{\sum_{i=1}^{n}\left[(\Delta P)_{e s t, i}-\overline{(\Delta P)_{e s t}}\right]^{2}}}$

$(\Delta P)_{a c t}$ is the actual pressure drop, $(\Delta P)_{e s t}$ is the estimated pressure drop, $\overline{(\Delta P)}$ act is the average of actual pressure drop, and $\overline{(\Delta P)}_{\text {est }}$ is the average of estimated pressure drop.

- Standard deviation (SD)

$$
S D=\left[\frac{n \sum_{i=1}^{n} E_{i}^{2}-\left(\sum_{i=1}^{n} E_{i}\right)^{2}}{n^{2}}\right]^{\frac{1}{2}}
$$


Table 3. Comparison of statistical analysis for two phase pressure drop models.

\begin{tabular}{|l|l|l|l|l|l|}
\hline Model & APE & AAPE & RMSE & R & SD \\
\hline Homogeneous model [13] & 17.758 & 24.323 & 0.120 & 0.847 & 0.441 \\
\hline Gray model [14] & 14.733 & 24.520 & 0.123 & 0.814 & 0.537 \\
\hline Beggs and Brill model [15] & -14.734 & 25.826 & 0.151 & 0.827 & 0.674 \\
\hline Duns and Ros model [16] & 8.970 & 22.399 & 0.097 & 0.887 & 0.572 \\
\hline Mukherjee and Brill model [17] & -3.251 & 29.041 & 0.116 & 0.832 & 0.757 \\
\hline Petalas and Aziz model [18] & -1.767 & 21.031 & 0.110 & 0.848 & 0.585 \\
\hline ANN model model [This work] & -0.143 & 15.243 & 0.057 & 0.960 & 0.509 \\
\hline
\end{tabular}

The results shown in table 3 . shows that the ANN model has the highest correlation coefficient and the minimum errors. However, the standard deviation for the ANN model is higher than that of the homogeneous model by about $13 \%$. Overall, the ANN model can be considered the best accuracy model in the current study.

\subsection{Evaluation of ANN model}

The test presented in the previous section was point by point test. Thus, the accuracy of the predicted results of any point doesn't affect the accuracy of others. However, in actual cases, the well bore is divided in many segments and the predicted result of a segment is assumed to be the inlet of the next one. Therefore, an evaluation of the ANN is necessary.

In this section two tests have been made to evaluate the ANN model, the first was to predict the pressure distribution along flowing wells. The second test was to predict the down-hole pressure of flowing wells.

\subsubsection{Prediction of well tubing flowing pressure distribution (traverse procedure)}

To evaluate the accuracy of ANN model in predicting the pressure distribution along the flowing wells, four pressure distribution data sets from EEMM field are used for this purpose. In addition, the comparison is also carried out with Petalas and Aziz [18] model as well as the PROSPER code. This code is a commercial code that is widely used in oil and gas industries. The data used for test is shown in table 4 . in addition to the inclination angle which is present in Appendix C

The method of calculation of the three models is the traverse method. In this method, the tube is divided into a number of segments and the calculations start with the segment at which flow and fluid data are known (well head). Then, the pressure drop along this segment is calculated. This pressure drop is used to calculate pressure at the end of the segment then, the fluid and flow data are evaluated at this point. These data are used as input to the next segment. The process is repeated until the end of the tube.

Figure 13 shows a comparison between the predicted and measured pressure distribution along the tubing of four flowing wells at EEMM field. It can be seen from the figure that the ANN model gives very good results for well EEMM\#1-A Fig. (13 a) followed by PROSPER code. Thus, PROSPER code and Petalas and Aziz model underestimated the pressure along the well tubing. For the second and third cases Fig. (13 b,c), all the tested models under-estimated the pressure distribution with PROSPER code and ANN model very close to each other and close to the measured data. For the last case, shown in Fig. (13 d), the PROSPER code over-estimated the pressure distribution while the other two models underestimated it. 
M.A. El-Kadi, M.A. Husien, S.M. El-Behery, H. Farouk "PREDICTION OF TWO-PHASE PRESSURE ..."

Table 4. Data entries of multiphase flow pressure drop models from EEMM Field.

\begin{tabular}{|l|l|l|l|l|l|l|l|l|l|l|}
\hline Well no. & $\begin{array}{l}\mathbf{q}_{\mathbf{L}} \\
\text { (STBD) }\end{array}$ & $\begin{array}{l}\gamma_{\mathbf{o}} \\
(\mathbf{A P I})\end{array}$ & $\gamma_{\mathrm{g}}$ & $\begin{array}{l}\text { MD } \\
\text { (ft) }\end{array}$ & $\begin{array}{l}\mathbf{W}_{\mathbf{c}} \\
\%\end{array}$ & $\begin{array}{l}\text { GOR } \\
\text { (SCF/STB) }\end{array}$ & $\begin{array}{l}\text { WHP } \\
\text { (PSI) }\end{array}$ & $\begin{array}{l}\text { Tubing } \\
\text { ID (in.) }\end{array}$ & $\begin{array}{l}\text { WHT } \\
\text { (F) }\end{array}$ & $\begin{array}{l}\text { BHT } \\
\text { (F) }\end{array}$ \\
\hline EEMM \#1A & 2000 & 45 & 0.897 & 3560 & $0 \%$ & 756 & 450 & 2.44 & 120 & 151.7 \\
\hline EEMM \#4 & 734 & 45 & 0.897 & 3400 & $0 \%$ & 1238 & 140 & 2.99 & 115 & 138.5 \\
\hline $\begin{array}{l}\text { EEMM \#40 } \\
\text { Chock 24/64 }\end{array}$ & 596 & 45 & 0.897 & 3529 & $5 \%$ & 771 & 451 & 2.44 & 75.2 & 150.8 \\
\hline $\begin{array}{l}\text { EEMM \#40 } \\
\text { Chock 32/64 }\end{array}$ & 628 & 45 & 0.897 & 3529 & $5 \%$ & 791 & 524 & 2.44 & 75.2 & 150.8 \\
\hline
\end{tabular}

To quantify the comparison, the same statistical analysis shown previously is applied for pressure distribution data and the results are shown in table 5. From this table it can be seen that the ANN model gives the most accurate results.

Table 5 Comparison of statistical analysis of predicting pressure distribution along wellbore.

\begin{tabular}{|l|l|l|l|l|l|}
\hline Model & APE & AAPE & RMSE & R & SD \\
\hline Petalas and Aziz model [18] & 25.23047 & 24.54687 & 193.2479 & 0.880708 & 0.12801 \\
\hline PROSPER code & 1.673633 & 7.942284 & 79.52317 & 0.978538 & 0.099993 \\
\hline ANN model [This work] & 3.818771 & 6.490947 & 29.97422 & 0.99599 & 0.078212 \\
\hline
\end{tabular}

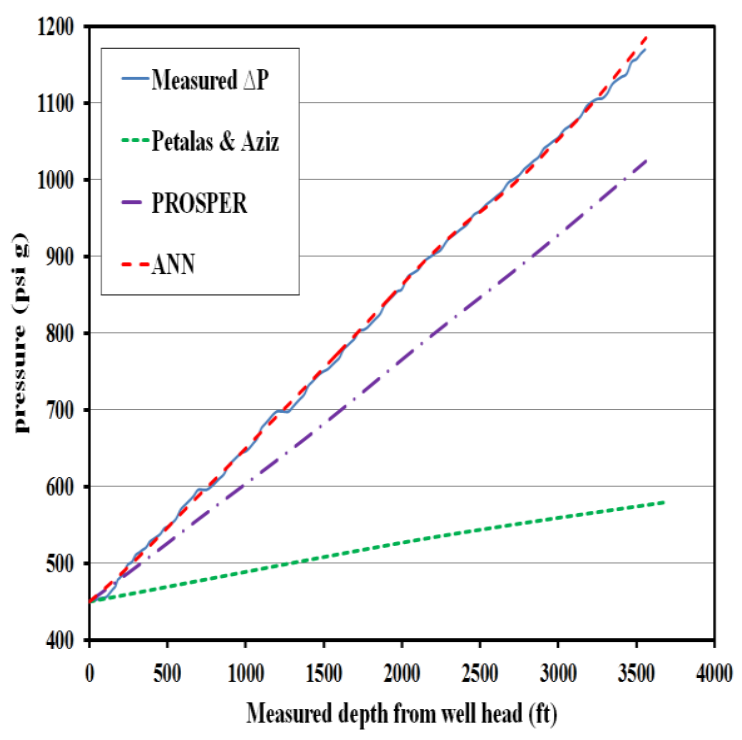

a) Well EEMM\#1-A.

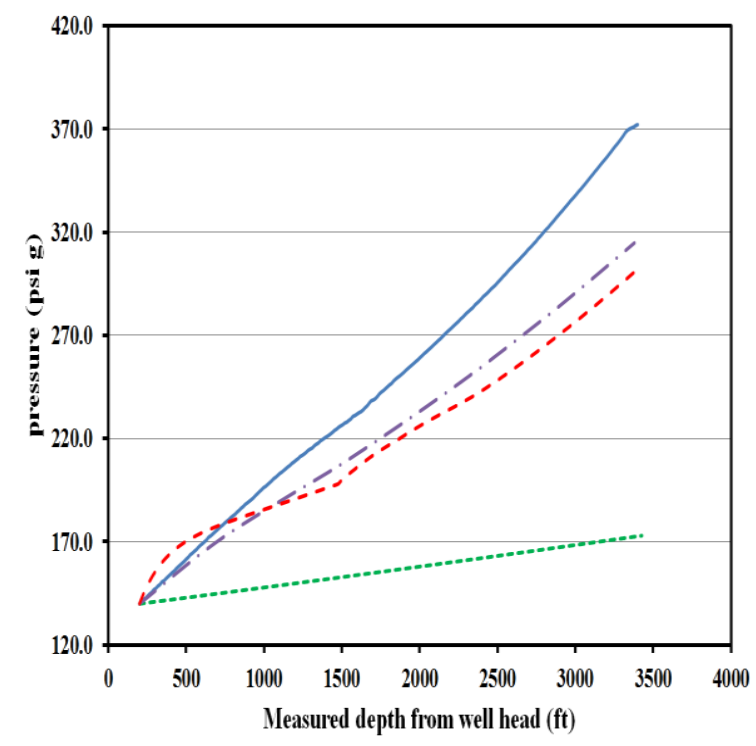

b) Well EEMM\#4. 


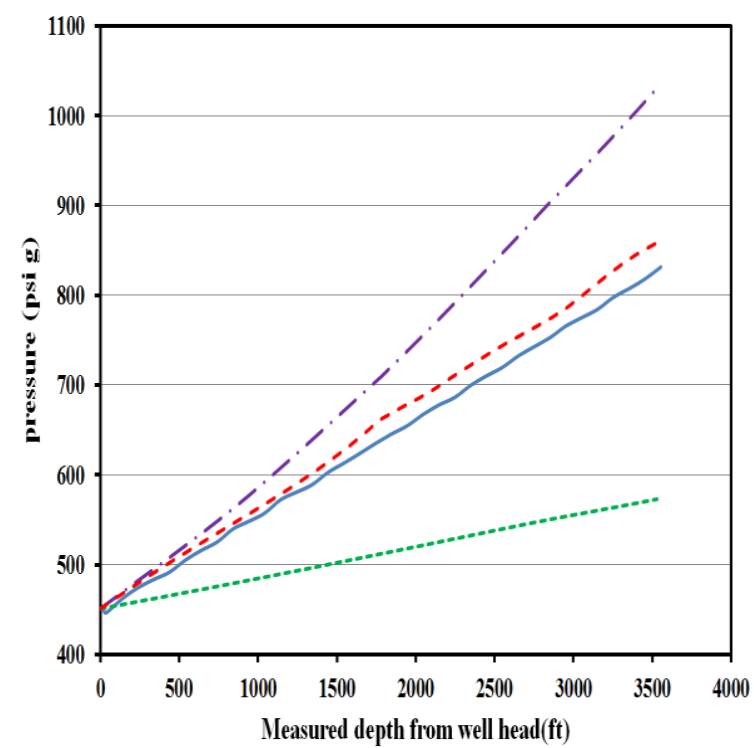

c) Well EEMM\#40 with 32"/64"chock.

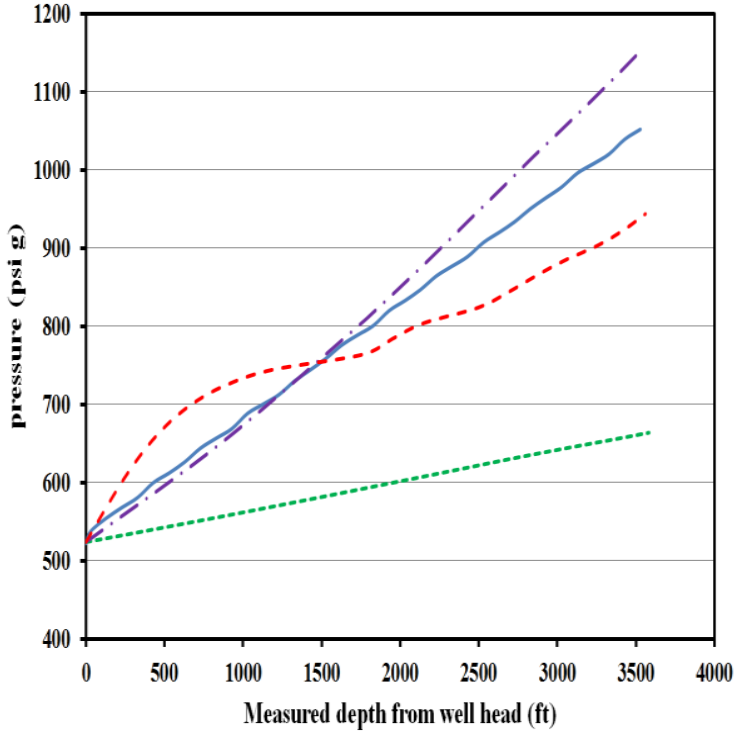

d) Well EEMM\#40 with 32"/64"chock.

Fig. 13. Comparison between predicted and measured pressure distribution along the tubing of four two-phase flowing wells at EEMM field.

\subsubsection{Prediction of down-hole pressure of wells}

In this section the ability of the ANN model to predict the down hole flowing pressure is investigated. Two sets of experimental data are used. The first set is from EEMM field and the operation conditions of this well were shown in table 4. Table 6. shows comparison between measured and predicted bottom hole flowing pressure (BHFP). It can be seen from this table that, the maximum error in the BHFP is $18.55 \%$.

Table 6. Comparison between measured and predicted BHFP.

\begin{tabular}{|l|l|l|l|l|l|l|l|}
\hline \multirow{2}{*}{ Well no } & \multirow{2}{*}{ measured } & \multicolumn{2}{|l|}{$\begin{array}{l}\text { Petalas and Aziz model } \\
{[18]}\end{array}$} & \multicolumn{2}{l|}{ PROSPER code } & \multicolumn{2}{l|}{$\begin{array}{l}\text { ANN model [this } \\
\text { work] }\end{array}$} \\
\cline { 2 - 8 } & $\begin{array}{l}\text { Predict } \\
\text { BHFP }\end{array}$ & $\%$ Error & Predict BHFP & $\%$ Error & $\begin{array}{l}\text { Predict } \\
\text { BHFP }\end{array}$ & $\%$ Error \\
\hline EEMM \#1A & 1170 & 580 & $50.43 \%$ & 1024 & $12.48 \%$ & 1185 & $-1.28 \%$ \\
\hline EEMM \#4 & 372 & 173 & $53.49 \%$ & 315 & $15.32 \%$ & 303 & $18.55 \%$ \\
\hline $\begin{array}{l}\text { EEMM \#40 } \\
\text { Chock 24/64 }\end{array}$ & 840 & 573 & $31.97 \%$ & 1030 & $-22.62 \%$ & 861 & $-2.50 \%$ \\
\hline $\begin{array}{l}\text { EEMM \#40 } \\
\text { Chock 32/64 }\end{array}$ & 1052 & 664 & $36.88 \%$ & 1152 & $-9.51 \%$ & 944 & $10.27 \%$ \\
\hline
\end{tabular}

The second test is given by Ebrahimi and Khamehchi [11]. The well's conditions, the measured BHFP, and predicted BHFP are given in table 7. Figure 14. shows the comparison between measured and predicted BHFP. It can be seen from this figure that, the most of data points lay within $\pm 30 \%$.

In conclusion, the ANN model can predict the pressure drop, pressure distribution, and BHFP with an acceptable accuracy.

Table 7. Data entries of Ebrahimi and Khamehchi [11] test case.

\begin{tabular}{|l|l|l|l|l|l|l|l|l|l|l|l|}
\hline $\begin{array}{l}\mathrm{q}_{\mathrm{L}} \\
(\mathrm{STBD})\end{array}$ & $\begin{array}{l}\gamma_{\mathrm{o}} \\
(\mathrm{API})\end{array}$ & $\gamma_{\mathrm{g}}$ & $\begin{array}{l}\mathrm{MD} \\
\mathrm{ft})\end{array}$ & $\mathrm{W}_{\mathrm{c}}$ & $\begin{array}{l}\text { GOR } \\
(\mathrm{SCF} / \mathrm{STB})\end{array}$ & $\begin{array}{l}\text { WHP } \\
(\mathrm{PSI})\end{array}$ & $\begin{array}{l}\text { Tubing } \\
\text { ID (in.) }\end{array}$ & $\begin{array}{l}\text { WHT } \\
(\mathrm{F})\end{array}$ & $\begin{array}{l}\text { BHT } \\
(\mathrm{F})\end{array}$ & $\begin{array}{l}\text { BHFP } \\
(\mathrm{psi}) \\
\text { Measured }\end{array}$ & $\begin{array}{l}\text { BHFP } \\
(\mathrm{PSI}) \\
\text { Calculated }\end{array}$ \\
\hline 3202.9 & 33 & 0.6 & 3170 & 0.02 & 450 & 220 & 2.64 & 80 & 112 & 3857 & 3080 \\
\hline 8467 & 29.5 & 0.81 & 7958 & 0.008 & 550 & 800 & 3.958 & 165 & 238 & 3720 & 3280 \\
\hline 3177 & 27.5 & 0.81 & 6617 & 0.648 & 554 & 450 & 3.74 & 162 & 234 & 3320 & 2370 \\
\hline 14108 & 24.6 & 0.81 & 6198 & 0.5 & 612 & 520 & 6.366 & 167 & 230 & 3174 & 3700 \\
\hline 2767.4 & 28 & 0.81 & 8323 & 0.957 & 512 & 265 & 3.5 & 160 & 236 & 2734 & 4165 \\
\hline 3811 & 51 & 0.65 & 13125 & 0.026 & 5327 & 2000 & 6.375 & 136 & 292 & 3375 & 3920 \\
\hline
\end{tabular}




\begin{tabular}{|l|l|l|l|l|l|l|l|l|l|l|l|}
\hline 8000 & 48.6 & 0.67 & 12795 & 0.025 & 5408 & 2400 & 6.375 & 133 & 290 & 4021 & 3580 \\
\hline 10546 & 11.2 & 0.65 & 7100 & 0.2 & 60 & 80 & 5.82 & 157 & 182 & 2900 & 2300 \\
\hline 1060 & 32.1 & 1.02 & 5524 & 0 & 437 & 186 & 2.992 & 99 & 202 & 2224 & 3566 \\
\hline 1713 & 32.8 & 1 & 6693 & 0.01 & 592 & 247 & 2.992 & 118 & 204 & 2379 & 3587 \\
\hline 1306 & 32 & 1.03 & 5933 & 0 & 341 & 203 & 2.992 & 111 & 202 & 2089 & 3583 \\
\hline
\end{tabular}

Fig. 14. BHFP prediction using ANN model (data source Ebrahimi and Khamehchi [11]).

\section{CONCLUSIONS}

The presented ANN is learned by a large data base collected from four different sources of 7581 data sets including 1165 data sets from Magapetco EEMM field. The data sets cover the most of flow regimes and all inclination angle ranges from $-90^{\circ}$ to $90^{\circ}$.

The selected network is a feed forward back-propagation network with ten inputs, two hidden layers, and 70 neurons in each hidden layer. The training, testing, and validation divisions are $70 \%, 15 \%$, and $15 \%$ respectively. The application input range of the presented ANN is tabulated in table 2. and out of this input range the accuracy of network output is not guaranteed. The following conclusions are obtained from the present study about ANN model.

1. The proposed ANN model is compared to the other two-phase pressure drop models resulted in a clear advantage of ANN. The ANN model predicts $48.27 \%$ of the data with an accuracy of $15 \%$ and $63.39 \%$ of the data with an accuracy of $30 \%$ for different flow regimes and different inclination angle ranges.
2. The ANN model has the highest correlation coefficient of 0.96 and the minimum errors compared to other tested models.

3. The ANN model presents the pressure distribution along the flowing accurately compared to the PROSPER code and Petalas and Aziz model [18]. In addition, the ANN model predicts BHFP with fair accuracy.

\section{REFERENCES}

[1] Ternyik IV, J., Bilgesu, H.I., Mohaghegh, S. and Rose, D.M., 1995. Virtual measurement in pipes: Part 1-Flowing bottom hole pressure under multi-phase flow and inclined wellbore conditions. In SPE Eastern Regional Meeting. Society of Petroleum Engineers.

[2] Mukherjee, H. and Brill, J.P., 1985. Pressure drop correlations for inclined two-phase flow. Journal of energy resources technology, 107(4), pp.549-554.

[3] Shippen, M.E. and Scott, S.L., 2002. A neural network model for prediction of liquid holdup in two-phase horizontal flow. In SPE Annual Technical Conference and Exhibition. Society of Petroleum Engineers. 
[4] Osman, E.S.A., 2004. Artificial neural network models for identifying flow regimes and predicting liquid holdup in horizontal multiphase flow. SPE production \& facilities, 19(01), pp.33-40.

[5] Osman, E.S.A., Ayoub, M.A. and Aggour, M.A., 2005. An artificial neural network model for predicting bottomhole flowing pressure in vertical multiphase flow. In SPE Middle East Oil and Gas Show and Conference. Society of Petroleum Engineers.

[6] Ozbayoglu, M.E. and Ozbayoglu, M.A., 2007. Flow pattern and frictional-pressure-loss estimation using neural networks for UBD operations. In IADC/SPE Managed Pressure Drilling \& Underbalanced Operations. Society of Petroleum Engineers.

[7] Mohammadpoor, M., Shahbazi, K., Torabi, F., Firouz, Q. and Reza, A., 2010. A new methodology for prediction of bottomhole flowing pressure in vertical multiphase flow in iranian oil fields using Artificial Neural Networks (ANNs). In SPE Latin American and Caribbean Petroleum Engineering Conference. Society of Petroleum Engineers.

[8] Ashena, R., Moghadasi, J., Ghalambor, A., Bataee, M., Ashena, R. and Feghhi, A., 2010. Neural networks in BHCP prediction performed much better than mechanistic models. In International Oil and Gas Conference and Exhibition in China. Society of Petroleum Engineers.

[9] Adebayo, A.R., Abdulraheem, A. and AlShammari, A.T., 2013. Promises of Artificial Intelligence Techniques in Reducing Errors in Complex Flow and Pressure Losses Calculations in Multiphase Fluid Flow in Oil Wells. In SPE Nigeria Annual International Conference and Exhibition. Society of Petroleum Engineers.

[10] Li, X., Miskimins, J. and Hoffman, B.T., 2014. A combined bottom-hole pressure calculation procedure using multiphase correlations and artificial neural network models. In SPE Annual Technical Conference and Exhibition. Society of Petroleum Engineers.
[11] Ebrahimi, A. and Khamehchi, E., 2015. A robust model for computing pressure drop in vertical multiphase flow. Journal of Natural Gas Science and Engineering, 26, pp.13061316.

[12] Demuth, H., Beale, M. and Hagan, M., 2008. Neural network toolbox ${ }^{\mathrm{TM}} 6$. User's guide

[13] Ali, S. F., 2009. Two-phase flow in a large diameter vertical riser. $\mathrm{PhD}$ Thesis, School of Engineering, Cranfield University.

[14] Gray, H. E. 1978. Vertical flow correlation gas wells. User's manual for API 14B, SSCSV Sizing Computer Program. second edition, API appendix B, 38-41

[15] Beggs, D.H. and Brill, J.P., 1973. A study of two-phase flow in inclined pipes. Journal of Petroleum technology, 25(05), pp.607-617.

[16] Duns Jr, H. and Ros, N.C.J., 1963. Vertical flow of gas and liquid mixtures in wells. In 6th world petroleum congress, Frankfurt, Section II, 22-PD6

[17] Mukherjee, H. and Brill, J.P., 1985. Pressure drop correlations for inclined two-phase flow. Journal of energy resources technology, 107(4), pp.549-554.

[18] Petalas, N. and Aziz, K., 1998. A mechanistic model for multiphase flow in pipes. In Annual Technical Meeting. Petroleum Society of Canada.

[19] Petalas, N. and Aziz, K., 1995. Stanford Multiphase Flow Database - User's manual Version 2. Petroleum Engineering Dept., Stanford University, California, USA.

[20] Meng, W., 1999. Low liquid loading gasliquid two-phase flow in near-horizontal pipes. PhD thesis, U. of Tulsa, Tulsa, Oklahoma, USA.

[21] Beggs, H.D., 1973. An experimental study of two-phase flow in inclined pipes. $\mathrm{PhD}$ thesis, $\mathrm{U}$. of Tulsa, Tulsa, Oklahoma, USA. 